\title{
Outcomes of selective nonoperative management of civilian abdominal gunshot wounds: a systematic review and meta- analysis
}

Aziza N. Al Rawahi ${ }^{1 \dagger}$, Fatma A. Al Hinai ${ }^{1}$, Jamie M. Boyd ${ }^{2}$, Christopher J. Doig ${ }^{2}$, Chad G. Ball ${ }^{1,3}$, George C. Velmahos ${ }^{4}$, Andrew W. Kirkpatrick ${ }^{1,2,3}$, Pradeep H. Navsaria ${ }^{5,6}$ and Derek J. Roberts ${ }^{7{ }^{*+}}$ (i)

\begin{abstract}
Background: Although mandatory laparotomy has been standard of care for patients with abdominal gunshot wounds (GSWs) for decades, this approach is associated with non-therapeutic operations, morbidity, and long hospital stays. This systematic review and meta-analysis sought to summarize outcomes of selective nonoperative management (SNOM) of civilian abdominal GSWs.

Methods: We searched electronic databases (March 1966-April 1, 2017) and reference lists of articles included in the systematic review for studies reporting outcomes of SNOM of civilian abdominal GSWs. We meta-analyzed the associated risks of SNOM-related failure (defined as laparotomy during hospital admission), mortality, and morbidity across included studies using DerSimonian and Laird random-effects models. Between-study heterogeneity was assessed by calculating $P^{2}$ statistics and conducting tests of homogeneity.

(Continued on next page)
\end{abstract}

\footnotetext{
* Correspondence: Derek.Roberts01@gmail.com

Meeting presentation: This study was presented as an oral presentation at Trauma 2016: The Trauma Association of Canada Annual Scientific Meeting in Halifax, Nova Scotia, Canada on May 6, 2016.

Work attributed to the Department of Surgery, University of Calgary, Calgary, Alberta, Canada

${ }^{\dagger}$ Aziza N. Al Rawahi and Derek J. Roberts contributed equally to this work.

${ }^{7}$ Division of Vascular and Endovascular Surgery, Department of Surgery, University of Ottawa, The Ottawa Hospital, Civic Campus, Room A280, 1053 Carling Avenue, Ottawa, Ontario K1Y 4E9, Canada

Full list of author information is available at the end of the article
}

(c) The Author(s). 2018 Open Access This article is distributed under the terms of the Creative Commons Attribution 4.0 International License (http://creativecommons.org/licenses/by/4.0/), which permits unrestricted use, distribution, and reproduction in any medium, provided you give appropriate credit to the original author(s) and the source, provide a link to the Creative Commons license, and indicate if changes were made. The Creative Commons Public Domain Dedication waiver (http://creativecommons.org/publicdomain/zero/1.0/) applies to the data made available in this article, unless otherwise stated. 
(Continued from previous page)

Results: Of 7155 citations identified, we included 41 studies [ $n=22,847$ patients with abdominal GSWs, of whom $6777(29.7 \%)$ underwent SNOM]. The pooled risk of failure of SNOM in hemodynamically stable patients without a reduced level of consciousness or signs of peritonitis was 7.0\% [95\% confidence interval $(\mathrm{Cl})=3.9-10.1 \% ; P^{2}=92.6 \%$, homogeneity $p<0.001$ ] while the pooled mortality associated with use of SNOM in this patient population was 0. $4 \%\left(95 \% \mathrm{Cl}=0.2-0.6 \% ; I^{2}=0 \%\right.$, homogeneity $\left.p>0.99\right)$. In patients who failed SNOM, the pooled estimate of the risk of therapeutic laparotomy was $68.0 \%\left(95 \% \mathrm{Cl}=58.3-77.7 \% ; R^{2}=91.5 \%\right.$; homogeneity $\left.p<0.001\right)$. Risks of failure of SNOM were lowest in studies that evaluated patients with right thoracoabdomen $\left(3.4 \% ; 95 \% \mathrm{Cl}=0-7.0 \% ; r^{2}=0 \%\right.$; homogeneity $p=0.45)$, flank (7.0\%; 95\% Cl=3.9-10.1\%), and back (3.1\%; 95\% Cl=0-6.5\%) GSWs and highest in those that evaluated patients with anterior abdomen (13.2\%; 95\% Cl=6.3-20.1\%) GSWs. In patients who underwent mandatory abdominopelvic computed tomography $(\mathrm{CT})$, the pooled risk of failure was $4.1 \%$ versus $8.3 \%$ in those who underwent selective CT ( $p=0.08)$. The overall sample-size-weighted mean hospital length of stay among patients who underwent SNOM was 6 days versus 10 days if they failed SNOM or developed an in-hospital complication.

Conclusions: SNOM of abdominal GSWs is safe when conducted in hemodynamically stable patients without a reduced level of consciousness or signs of peritonitis. Failure of SNOM may be lower in patients with GSWs to the back, flank, or right thoracoabdomen and be decreased by mandatory use of abdominopelvic CT scans.

Keywords: Abdominal gunshot wounds, Selective nonoperative management, Penetrating trauma, Wounds and injuries

\section{Background}

Mandatory laparotomy has been standard of care for patients with abdominal gunshot wounds (GSWs) for decades. However, this approach is associated with unnecessary, including non-therapeutic (where intra-abdominal injuries are found that do not require intervention) and negative (where no intra-abdominal injuries are found), laparotomies [1-3]. Further, mandatory laparotomy in patients with abdominal GSWs has been linked with a $22-41 \%$ risk of postoperative complications (e.g., surgical site infections, gastrointestinal ileus, pneumonia, and venous thromboembolism) [4, 5] and a 5- to 9-day length of hospital stay [6-8].

Selective nonoperative management (SNOM) is frequently conducted in trauma centers in patients with penetrating abdominal trauma who are hemodynamically stable without signs of diffuse peritonitis or evisceration. Although SNOM has been relatively widely adopted for abdominal stab wounds $[1,3,9]$, the concept has not been as embraced for GSWs given the higher associated incidence of visceral and abdominal vascular injuries and the morbidity and mortality associated with missed injuries $[9,10]$. Therefore, the practice of SNOM for abdominal GSWs remains controversial among some surgeons.

The cornerstone of SNOM lies on the principle of serial physical examinations of patients without a reduced level of consciousness by qualified surgeons or experienced surgical residents. Over the last two decades, there has also been an interest in using abdominopelvic computed tomography (CT) scans as an adjunct when conducting SNOM $[11,12]$. Proponents suggest that CT scans may better characterize bullet trajectory and have been reported to detect injuries with a sensitivity and specificity exceeding 90\% [12]. Opponents argue that it is associated with false negative and positive test results and lacks accuracy in detecting some (e.g., intestinal and diaphragmatic) injuries [13].

There have been no randomized controlled trials to date that have evaluated the outcomes of SNOM versus mandatory laparotomy for management of civilian abdominal GSWs. Moreover, results of cohort studies of this injury management strategy have been variable. To evaluate the potential safety of this approach, the purpose of this systematic review and meta-analysis was to summarize outcomes associated with use of SNOM in cohort studies of civilians with abdominal GSWs. We hypothesized that SNOM of abdominal GSWs would be safe (associated with a small risk of failure, morbidity, and mortality) when conducted in highly experienced trauma centers. We also sought to determine whether variability in reported outcomes of SNOM across cohort studies may be due to differences in study risks of bias, practices of SNOM across trauma centers and countries, or study patient injury patterns (e.g., whether the entry wound of the included patients was predominantly in the anterior abdomen, thoracoabdomen, flank, or back).

\section{Methods \\ Protocol}

Our methods were pre-specified in a detailed protocol created according to the Preferred Reporting Items in Systematic Reviews and Meta-Analyses statement [14] and the Meta-analysis of Observational Studies in Epidemiology 
(MOOSE) proposal (see the completed MOOSE checklist in Additional file 1: digital content S1) [15].

\section{Search strategy}

With the assistance of a medical librarian/information scientist, we searched PubMed, Ovid MEDLINE and EMBASE, and the Cochrane Library from their inception to April 1, 2017, without language restrictions. Using a combination of Medical Subject Heading (MeSH) and Emtree terms and keywords, we created search filters covering the themes SNOM, penetrating injury/GSW, and abdomen. These filters were combined in our final database searches using the Boolean operator "AND." Our complete search strategies are shown in Additional file 2: digital content S2. To identify additional studies, we used the PubMed "related articles" feature, hand-searched references of included original and relevant review articles identified during the search, and wrote several authors who had published on the topic.

\section{Selection criteria}

Independently and in duplicate, two investigators (ANAR, FAAH) screened the titles and abstracts of citations identified during the search, reviewed potentially relevant articles in full, and decided on study inclusion. We used the following inclusion criteria: (1) study participants were adult (mean age $\geq 16$ years) civilian trauma patients with GSWs to the abdomen; (2) some or all of the included patients underwent SNOM of their abdominal GSWs; (3) reported outcomes included SNOM failure, morbidity, mortality, and/or patient hospital length of stay (LOS); and (4) the study used a cohort design. We distinguished cohort studies from case series using the criteria developed by Dekkers et al. and included controlled (which included a comparable control group of patients without diffuse peritonitis or hemodynamic instability that underwent mandatory laparotomy) and uncontrolled cohort studies in the systematic review [16]. We excluded conference abstracts. Study eligibility disagreements were resolved by consensus. Inter-investigator agreement on article inclusion was assessed using kappa (к) statistics [17]. When the same data were reported across multiple studies, the study with the larger sample size or that provided the most information on SNOM-associated outcomes was included.

\section{Definitions}

We subdivided the abdomen into the anterior abdomen, thoracoabdomen, bilateral flanks, and back. We defined the anterior abdomen as the region bounded superiorly by the costal margins, laterally by the anterior axillary lines, and inferiorly by the inguinal creases [18]. The thoracoabdomen was defined as the region enclosed by the nipples (or tips of the scapulae) superiorly and the costal margin inferiorly [18]. We defined the flanks as the region bounded by the costal margins, anterior and posterior axillary lines, and iliac crests [18]. Finally, the back was defined as the region bounded superiorly by the inferior scapular tips, laterally by the posterior axillary lines, and inferiorly by the iliac crests [18].

\section{Data extraction}

Three reviewers (ANAR, FAAH, JMB) independently extracted data from included studies in duplicate. Data extracted included (1) study design, temporality, and setting; (2) trauma center and study cohort characteristics [e.g., recruitment period and mean/median patient age and Injury Severity Scale (ISS) score], number of trauma patients and abdominal GSWs assessed per year, and the anatomical regions of the abdomen injured by GSWs; (3) number of patients who underwent SNOM and details regarding SNOM practices (frequency of clinical and laboratory examinations, mandatory versus selective use of CT, duration of observation, and type and duration of follow-up); and (4) outcomes associated with use of SNOM.

\section{Primary and secondary outcomes}

The primary outcome was the risk of failure of SNOM. We defined failure as the conduct of laparotomy on a patient undergoing SNOM for an abdominal GSW during their hospital admission. Secondary outcomes included therapeutic and unnecessary laparotomy among patients who failed SNOM, in-hospital mortality, reported morbidities associated with SNOM, and hospital LOS. Unnecessary laparotomy was defined as either negative (where no injury was identified during laparotomy) or non-therapeutic (where an injury was found during laparotomy that did not require surgical intervention).

\section{Risk of bias assessment}

The risk of bias of the included studies was assessed by two independent investigators with graduate training in epidemiology (ANAR, FAAH) using a modified version of the Quality in Prognosis Studies (QUIPS) tool [19]. This tool includes 24 decision items that cover five quality domains of interest, including (1) patient selection, (2) study attrition, (3) prognostic factor measurement, (4) outcome measurement, and (5) statistical analysis and reporting. We scored the adequacy of reporting for each item of the above five QUIPS domains as "yes," "no," or "unclear." This scoring led to the overall judgment of low, moderate, or high risk of bias per quality domain. Disagreements regarding study risk of bias were resolved by consensus. 


\section{Statistical analyses}

We calculated study estimates of the risk of failure of SNOM and therapeutic and unnecessary laparotomy, reported morbidities, and in-hospital mortality associated with use of SNOM in patients with abdominal GSWs. We determined standard errors and 95\% confidence intervals (CIs) for these estimates using Clopper-Pearson exact methods [20]. We applied a continuity correction of 1 to estimates with a zero numerator or denominator to estimate their standard error [21].

DerSimonian and Laird random-effects models were used to calculate pooled estimates of the risk of outcomes across the included studies [22]. Summary mean and median LOS across studies were calculated by weighting these estimates by study sample sizes. Heterogeneity in pooled estimates was assessed by calculating $I^{2}$ inconsistency and $\mathrm{Q}$ statistics and conducting tests of homogeneity ( $p$ value $<0.10$ considered significant given the low power of these tests) [23]. The $I^{2}$ statistic represents the percentage of variation between studies due to factors other than chance. $I^{2}$ statistics of $>25 \%,>50 \%$, and $>75 \%$ were considered to represent low, moderate, and high degrees of heterogeneity, respectively [24]. A test of homogeneity $p$ value $<0.10$ was considered to indicate more heterogeneity than would be expected between studies due solely to chance [24].

In the presence of at least low inter-study heterogeneity, we conducted stratified meta-analyses and meta-regression to determine whether our pooled risk estimates varied across a number of study-level covariates selected a priori. Covariates of interest included study setting (USA, South Africa, or other) and temporality (prospective versus retrospective), study patient injury patterns [anterior abdominal, right thoracoabdominal, isolated renal or hepatic/right upper quadrant (RUQ), back, or flank GSWs], and reported SNOM practices (serial physical examinations done by surgeons or surgical residents and mandatory versus selective use of abdominopelvic CT scans).

We examined for evidence of small study effects potentially due to publication bias by creating funnel plots and conducting Begg's funnel plot asymmetry test [25]. We used the Duval and Tweedie "trim and fill" method to evaluate the potential influence of publication bias on our pooled estimates $[26,27]$. Using this method, small outlying studies were first "trimmed" (removed until funnel plots were symmetric). The remaining study results were then used to re-estimate the theoretically unbiased center of the plot before it was "filled" (the missing outlying study results and their theoretical counterparts were replaced around the re-estimated center), permitting calculation of a publication bias-adjusted pooled risk estimate [26-29]. Stata version 13 (Stata Corp., College Station, TX, USA) was used for all analyses.

\section{Results}

\section{Study selection}

Among 7155 citations identified by the search, 41 studies $[n=22,847$ patients with abdominal GSWs, of whom 6777 (29.7\%) underwent SNOM] were included in the systematic review (Fig. 1). There was excellent inter-investigator agreement on inclusion of full-text articles $(\kappa$-statistic $=0.82 ; 95 \% \mathrm{CI}=0.45-1.00)$.

We found no controlled studies of SNOM that included a comparable control group of patients without diffuse peritonitis or hemodynamic instability that underwent mandatory laparotomy. Instead, all included studies examined outcomes of SNOM in a cohort of patients with abdominal GSWs to the anterior or other regions of the abdomen. Six studies reported outcomes of SNOM in patients with renal GSWs [30-34] while 5 reported SNOM outcomes in patients with hepatic GSWs [35-39]. Another three studies included patients with GSWs to the RUQ [40-42], one with GSWs to the back [43], and one with GSWs to the flank [44].

\section{Characteristics of the included studies/patients and SNOM practices}

Characteristics of the included studies/patients and SNOM practices are shown in Table 1 . Studies were published between 1966 and 2017, with the majority (63.4\%) being published after the year 2000. Most were conducted at high-volume, level 1 trauma centers in the USA (70.7\%) or South Africa (19.5\%). Twenty-two (53.7\%) studies were prospective and 19 (46.3\%) were retrospective. Mean ages of patients ranged between 22.8 and 30.6 years, and 18 (43.9\%) studies reported the mean ISS score, which ranged between 3 and 22.5.

In all studies, hemodynamically stable patients without a reduced level of consciousness and no signs of peritonitis were selected for SNOM. Twenty-one (51.2\%) studies reported that patients were admitted to a dedicated, monitored observation area for 12-48 h before being transferred to a floor bed or discharged from hospital [30, 33, 38-56]. Four (19\%) of these 21 studies reported that patients underwent serial physical examinations at time intervals ranging from every half-hour to $4 \mathrm{~h}[30,48,53,54]$. Physical examinations were reportedly performed by an attending trauma surgeon in $5(12.2 \%)$ studies $[46,51,52,57,58]$ and a surgical resident in $4(9.8 \%)$ studies $[30,39,42,55]$. Sixteen (39.0\%) studies reported that patients also had serial measurements of hemoglobin, hematocrit, and white blood cell (WBC) counts during the post-GSW observation period [33, 34, 38, 40-47, 49-51, 59, 60]. Patients selected for SNOM were evaluated with abdominopelvic CT scans with intravenous contrast (in either a mandatory or selective fashion) in 33 (80.5\%) studies [11, 12, 30-34, 36-41, 43-52, 55, 59-67]. 


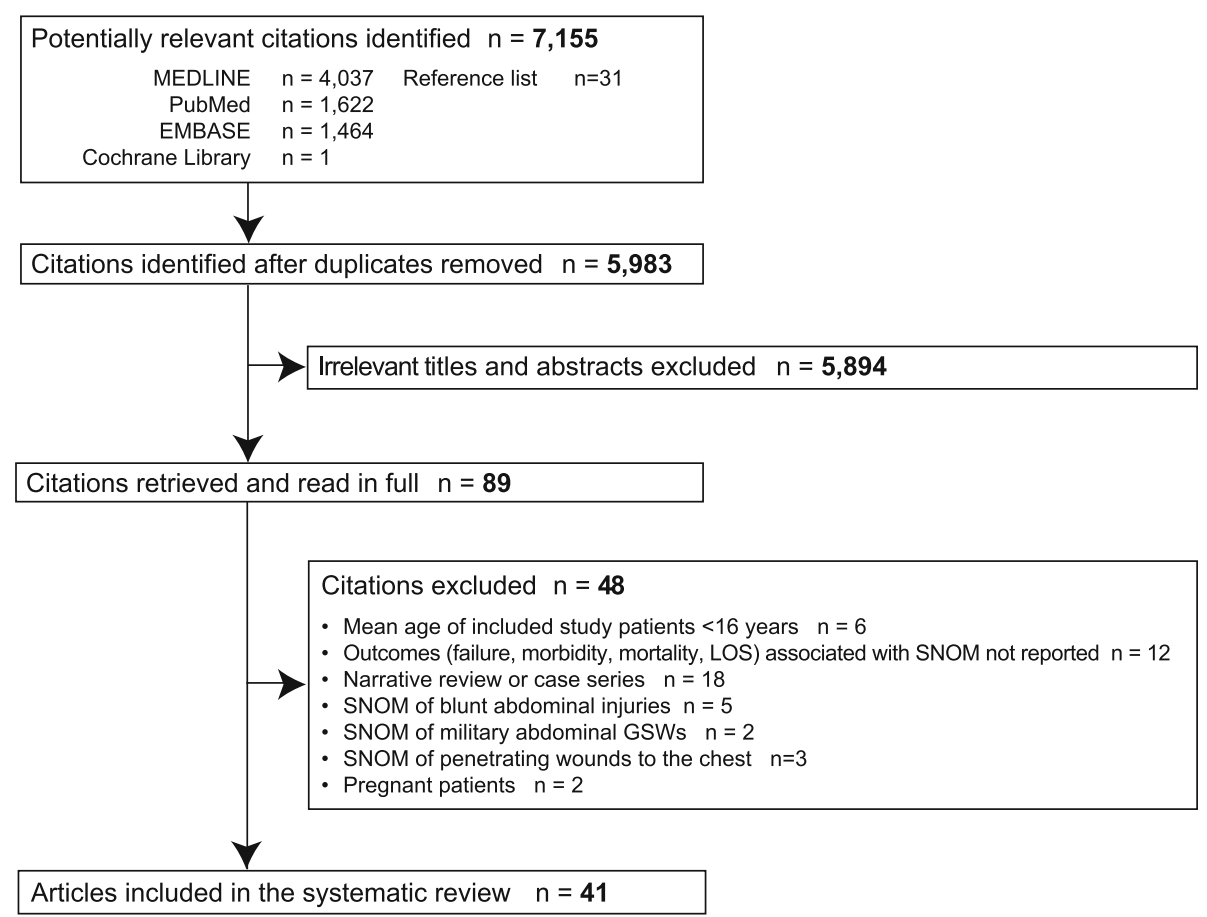

Fig. 1 Flow of articles through the systematic review, where LOS indicates length of stay, GSWs gunshot wounds, and SNOM selective nonoperative management

\section{Risk of bias assessment}

Table 2 summarizes the risk of bias assessment for all included studies. Most studies had a low to moderate risk of bias. Six (14.6\%) studies demonstrated a high risk of bias in at least 1 modified QUIPS tool domain $[12,55,56,58,62$, 68]. Thirty-four (82.9\%) studies showed a moderate-to-high risk of study attrition bias due to inadequate reporting of information about whether patients were lost to follow-up [12, 30-34, 36-41, 43-48, 50-64, 66-68]. Twenty (48.7\%) studies demonstrated a moderate-to-high risk of prognostic factors measurement bias because (1) the authors did not report data on the grade of injury suffered by study patients in 18 (43.9\%) studies [11, 12, 30, 39, 41-45, 48, 51-55, 57, 62, 68], ISS score of the patients in 15 (36.6\%) studies [11, 38, 40-43, $48,49,51-55,58,68]$, or age of the patients in $4(9.8 \%)$ studies $[41,48,53,68]$; (2) there was no standardized policy for SNOM adopted in 9 (22.0\%) studies [12, 31, 32, 43, 54, 58, 62-64]; or (3) patients were managed operatively based on the decision of the attending surgeon rather than a defined protocol or decision algorithm in $3(7.3 \%)$ studies [31, 58, 63]. Thirteen (31.7\%) studies showed a moderate-to-high risk of outcome measurement bias because (1) the definition of failure of SNOM was based on the timing from admission to the operating room in 2 (4.9\%) studies [31, 62]; (2) failure of SNOM was solely based on CT findings without considering physical examination findings in 3 (7.3\%) studies [12, 32, 55]; or (3) a clear definition of failure of SNOM was not provided in $8(19.5 \%)$ studies [34, 37, 38, 56, 58, 63, 64, 68].
One study included 12,707 patients that sustained abdominal GSWs between 2002 and 2008 and were included in the National Trauma Data Bank (NTDB) [62], which contains data collected from approximately 900 trauma centers in the USA. This study likely included duplicate patients from other American studies published during the same period $[9,12,31,32,37,44,60$, $63,66]$. Further, a number of other studies used the same data source to identify patients, but looked at different outcomes and/or patient populations [33, 39, 40, $43,45,50,59,67]$. However, it was not possible to determine the amount of overlap or duplication of patients with certainty between these studies, and therefore, the influence of overlap was explored in a post hoc sensitivity analysis described below.

\section{Outcomes associated with use of SNOM for abdominal GSWs \\ Primary outcome}

The pooled estimate of the risk of failure of SNOM for abdominal GSWs across 28 studies that reported data on this outcome was $7.0 \%$ (95\% CI =3.9-10.1\%) (Fig. 2). There was a high degree of heterogeneity between these studies $\left(I^{2}=\right.$ 92.6\%, homogeneity $p<0.001$ ). In patients who failed SNOM, the pooled estimate of the risk of therapeutic laparotomy was $68.0 \% \quad$ (95\% CI $=58.3-77.7 \% ; \quad I^{2}=91.5 \%$; homogeneity $p<0.001)$ while that of unnecessary laparotomy was $28.1 \%$ (95\% CI $=19.0-37.1 \% ; I^{2}=90.6 \%$, homogeneity $\left.p<0.001\right)$. 


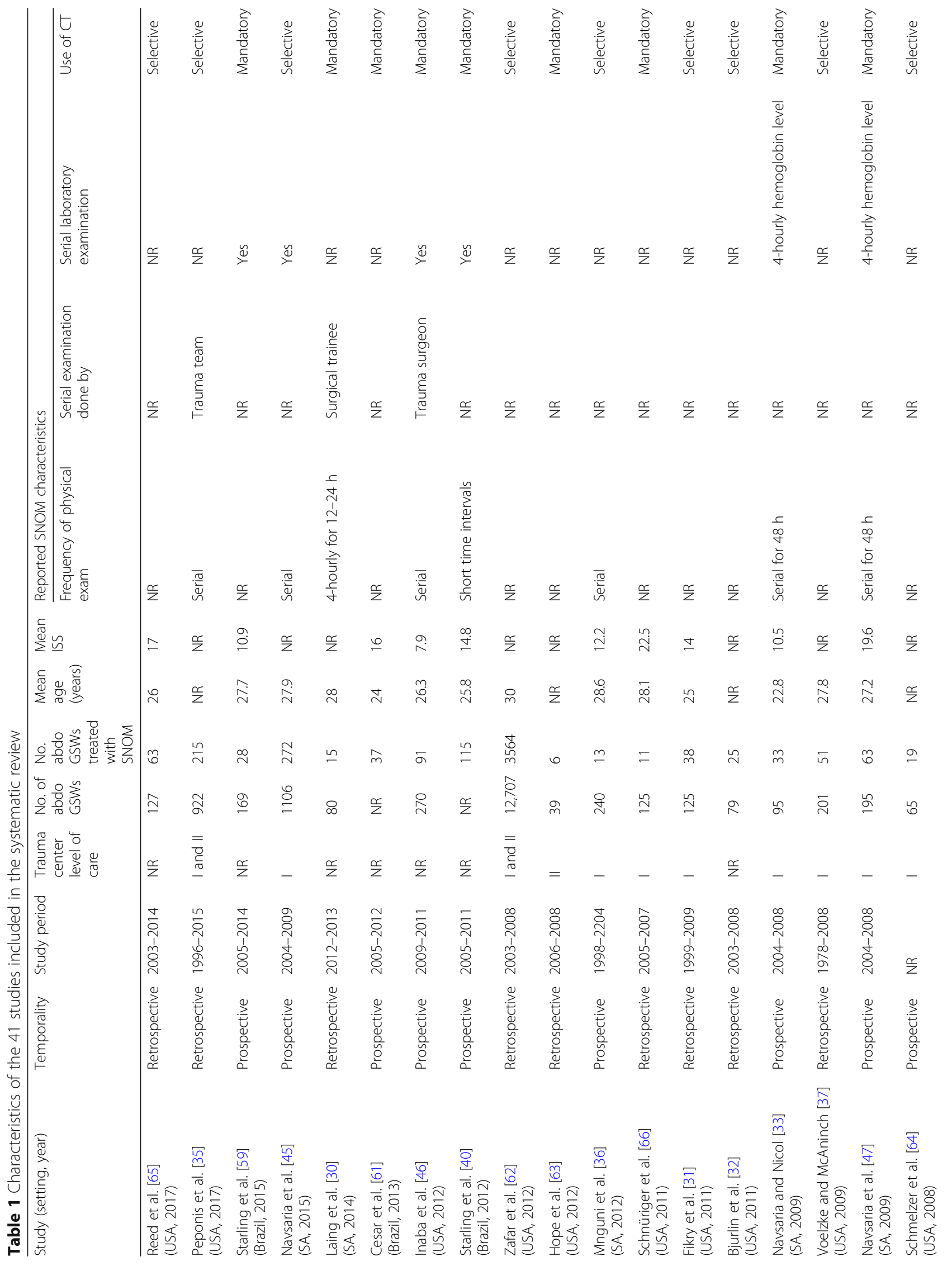




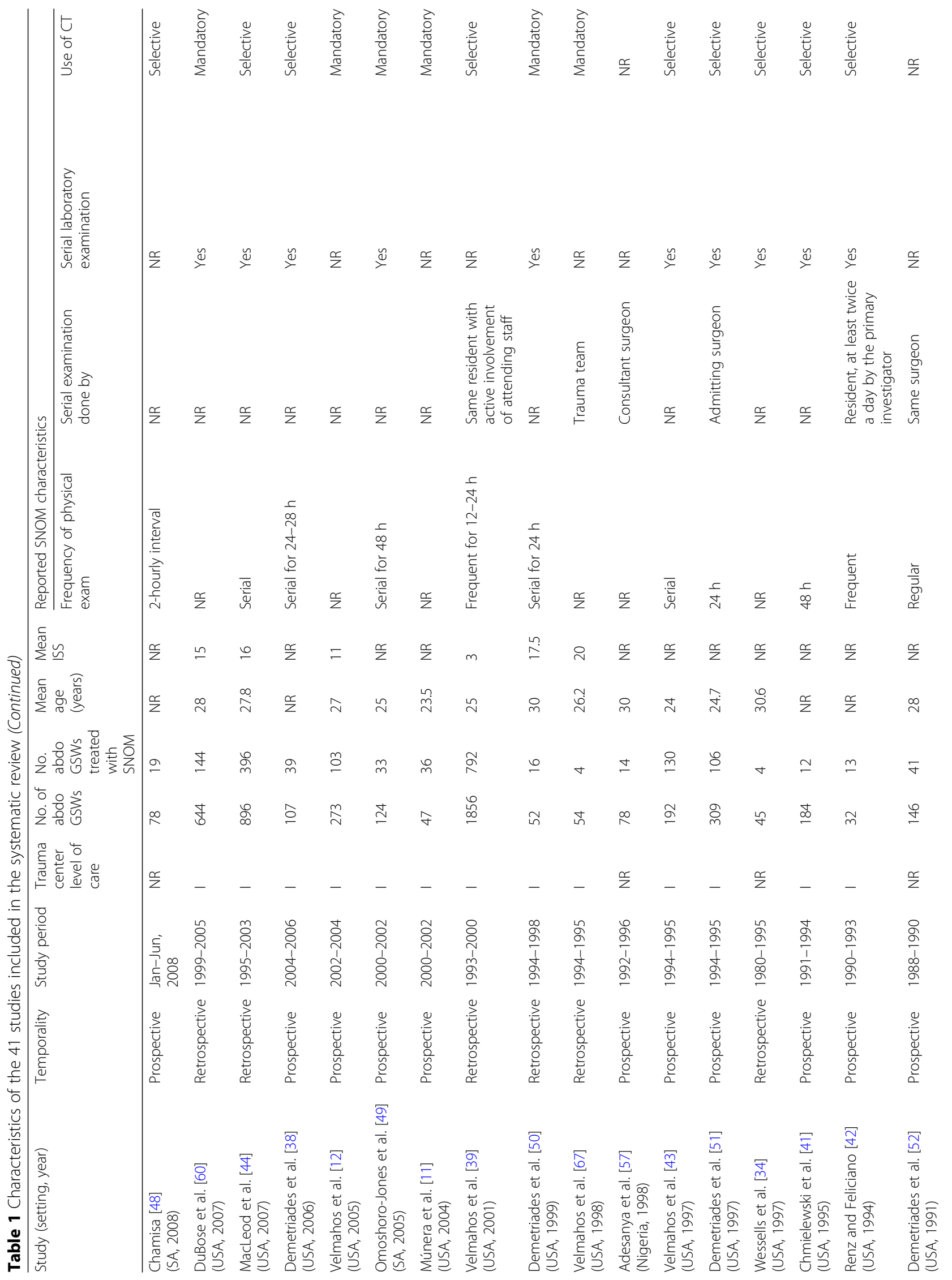




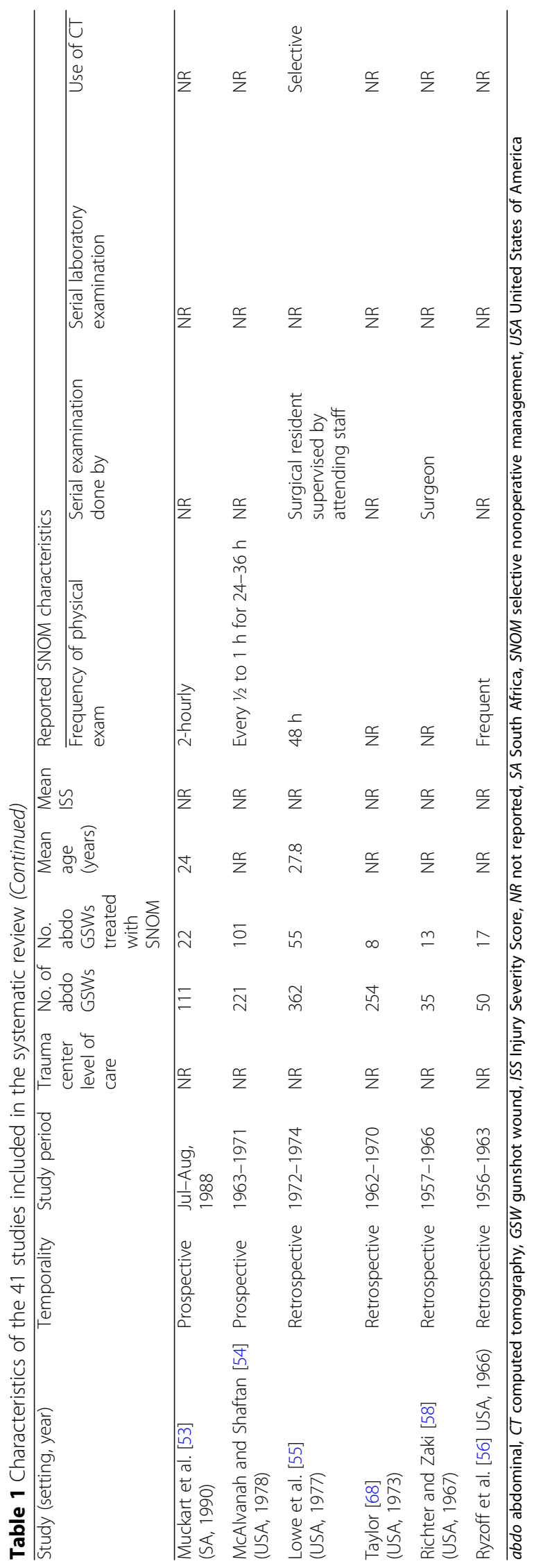


Table 2 Risk of bias assessment of the 41 included studies

\begin{tabular}{|c|c|c|c|c|c|}
\hline Study & $\begin{array}{l}\text { Study } \\
\text { participation }\end{array}$ & $\begin{array}{l}\text { Study } \\
\text { attrition }\end{array}$ & $\begin{array}{l}\text { Prognostic factors } \\
\text { measurement }\end{array}$ & $\begin{array}{l}\text { Outcome } \\
\text { measurement }\end{array}$ & $\begin{array}{l}\text { Statistical analysis and } \\
\text { reporting }\end{array}$ \\
\hline Reed et al. [65] & Low & Moderate & Low & Low & Low \\
\hline Peponis et al. [35] & Moderate & Moderate & Low & Low & Low \\
\hline Starling et al. [59] & Low & Moderate & Low & Low & Low \\
\hline Navsaria et al. [45] & Low & Moderate & Moderate & Low & Low \\
\hline Laing et al. [30] & Moderate & Moderate & Low & Low & Moderate \\
\hline Cesar et al. [61] & Low & Moderate & Low & Low & Low \\
\hline Inaba et al. [46] & Low & Moderate & Low & Low & Low \\
\hline Starling et al. [40] & Moderate & Moderate & Low & Low & Low \\
\hline Zafar et al. [62] & Low & High & Moderate & Moderate & Low \\
\hline Hope et al. [63] & Low & Moderate & Moderate & Moderate & Low \\
\hline Mnguni et al. [36] & Moderate & Moderate & Low & Low & Low \\
\hline Schnüriger et al. [66] & Low & Moderate & Low & Low & Moderate \\
\hline Fikry et al. [31] & Low & Moderate & Moderate & Moderate & Low \\
\hline Bjurlin et al. [32] & Moderate & Moderate & Moderate & Moderate & Moderate \\
\hline Navsaria and Nicol [33] & Low & Moderate & Low & Low & Low \\
\hline $\begin{array}{l}\text { Voelzke and McAninch } \\
\text { [37] }\end{array}$ & Low & Moderate & Low & Moderate & Moderate \\
\hline Navsaria et al. [47] & Low & Moderate & Low & Low & Low \\
\hline Schmelzer et al. [64] & Low & Moderate & Moderate & Moderate & Low \\
\hline Chamisa [48] & Low & Moderate & Moderate & Low & Low \\
\hline DuBose et al. [60] & Low & Moderate & Low & Low & Low \\
\hline MacLeod et al. [44] & Low & Moderate & Low & Low & High \\
\hline Demetriades et al. [38] & Moderate & Moderate & Moderate & Moderate & Low \\
\hline Velmahos et al. [12] & Low & Moderate & Moderate & Moderate & Moderate \\
\hline $\begin{array}{l}\text { Omoshoro-Jones et al. } \\
\text { [49] }\end{array}$ & Low & Low & Low & Low & Low \\
\hline Múnera et al. [11] & Low & Low & Low & Low & Moderate \\
\hline Velmahos et al. [39] & Low & Moderate & Low & Low & Low \\
\hline Demetriades et al. [50] & Low & Moderate & Low & Low & Moderate \\
\hline Velmahos et al. [67] & Low & Moderate & Low & Low & Low \\
\hline Adesanya et al. [57] & Low & Moderate & Moderate & Low & Moderate \\
\hline Velmahos et al. [43] & Low & Moderate & Moderate & Low & Low \\
\hline Demetriades et al. [51] & Low & Moderate & Low & Low & Moderate \\
\hline Wessells et al. [34] & Low & Moderate & Moderate & Moderate & Moderate \\
\hline Chmielewski et al. [41] & Moderate & Moderate & Moderate & Low & Moderate \\
\hline Renz and Feliciano [42] & Low & Low & Moderate & Low & Low \\
\hline Demetriades et al. [52] & Low & Moderate & Moderate & Low & Moderate \\
\hline Muckart et al. [53] & Low & Low & Low & Low & Moderate \\
\hline $\begin{array}{l}\text { McAlvanah and Shaftan } \\
\text { [54] }\end{array}$ & Low & Moderate & Moderate & Low & Low \\
\hline Lowe et al. [55] & Moderate & Moderate & Moderate & High & High \\
\hline Taylor [68] & Moderate & High & High & High & High \\
\hline Richter and Zaki [58] & Moderate & Moderate & High & Moderate & Moderate \\
\hline Ryzoff et al. [56] & Moderate & Moderate & Moderate & Moderate & Moderate \\
\hline
\end{tabular}




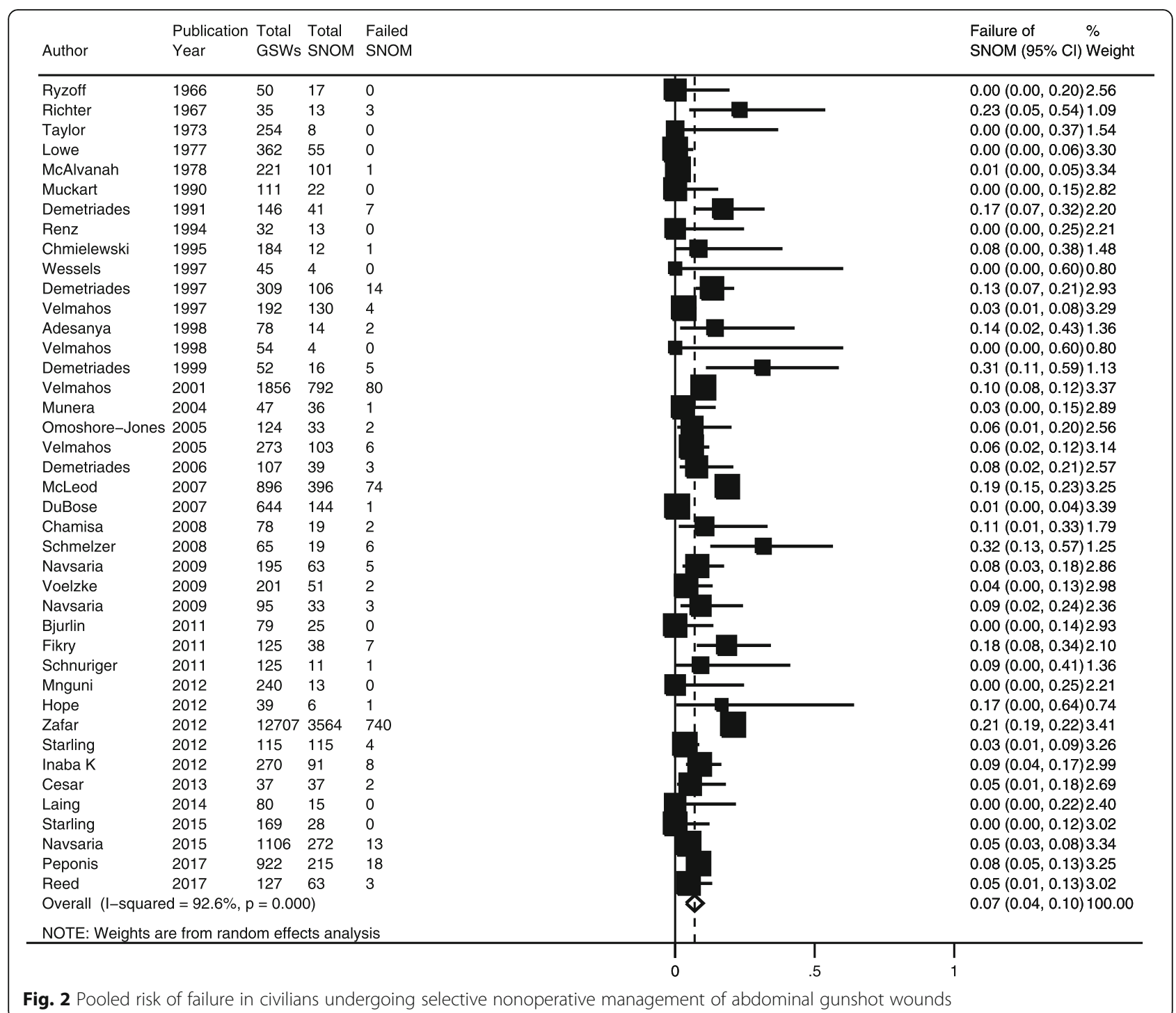

Twenty studies (48.8\%) reported the length of time from admission to delayed laparotomy in patients that failed SNOM. The weighted mean and median time between admission and delayed laparotomy in patients selected for a trial of SNOM ( $n=16$ studies, $39.0 \%$ ) was 40.6 and $21.2 \mathrm{~h}$, respectively [12, 31, 35, 38, 40, 41, 43, $45-47,49,51,60,63,65,66]$.

Indications for delayed laparotomy (as well as intraoperative findings) in patients who failed SNOM were described in $17(41.5 \%)$ of the included studies and are described in detail in the table in Additional file 3: digital content S3. These most commonly included development of peritonitis (38.8\%) $[12,31,33,35,46-48,50,52]$, worsening abdominal tenderness $(35.7 \%)[35,41,43,45,51]$, or fever $(11.2 \%)$ [33, 41, 43, $45,46,48,63]$. Less common reasons included development of new tachycardia $(8.2 \%)[41,46,47]$ or hypotension $(1.0 \%)$ [60]. Others included rising WBC counts $(6.1 \%)[46,63]$ or falling hematocrit levels (6.1\%) [31-33, 37, 46, 47, 50, 51].

\section{Secondary outcomes}

Morbidity and mortality of patients that underwent SNOM Pooled estimates of the risk of complications associated with SNOM are reported in Table 3. Of these, atelectasis and GSW infections were most common, with pooled risk estimates of $21.2 \%$ (95\% CI $=7.0-35.4 \%$, $I^{2}=0.0 \%$, homogeneity $\left.p=0.36\right)$ and $6.0 \%(95 \% \mathrm{CI}=$ $3.1-8.9 \%, I^{2}=0 \%$, homogeneity $p=0.71$ ), respectively. The pooled estimate of the risk of any intrathoracic complication (pneumothorax, hemothorax, empyema, or pleural effusion) was $11.6 \%\left(95 \% \mathrm{CI}=3.5-19.7 \% ; I^{2}=\right.$ $79.0 \%$; homogeneity $p=0.005)$. Three studies $(7.7 \%)$ reported biliary fistula formation after SNOM in patients with liver GSWs, with a pooled risk of 3.5\% (95\% CI = $1.0-8.0 \% ; I^{2}=61.8 \%$; homogeneity $p=0.07$ ) $[12,33,42]$.

Among 10 (24.4\%) studies that reported data on in-hospital mortality [31, 35, 39, 40, 44, 45, 54, 58, 62, 65], 
Table 3 Pooled risk of complications associated with selective nonoperative management of abdominal gunshot wounds

\begin{tabular}{|c|c|c|c|c|c|}
\hline Complications & No. of studies & No. of patients & Pooled risk, \% (95\% Cl) & $P^{2}$ statistic, $\%$ & $p$ value for the test of homogeneity \\
\hline Pneumonia & 7 & 20 & $1.4(0.1-2.7)$ & 61.7 & 0.02 \\
\hline Atelectasis & 2 & 7 & $21.2(7.0-35.4)$ & 0 & 0.36 \\
\hline ARDS & 5 & 8 & $1.0(0-2.6)$ & 43.8 & 0.13 \\
\hline Sepsis & 4 & 6 & $0.3(0-1.0)$ & 36.2 & 0.20 \\
\hline Any intra-thoracic complication* & 5 & 25 & $11.6(3.5-19.7)$ & 79.0 & 0.001 \\
\hline Any intra-abdominal collection ${ }^{\dagger}$ & 7 & 16 & $0.8(0.3-1.2)$ & 0 & 0.49 \\
\hline Hematuria & 2 & 3 & $1.5(0.5-2.5)$ & 98.8 & 0.003 \\
\hline Biliary fistula & 3 & 8 & $3.5(0-8.0)$ & 99.5 & $<0.001$ \\
\hline Gunshot wound infection & 2 & 3 & $6.0(3.1-8.9)$ & 0 & 0.71 \\
\hline Deep venous thrombosis & 2 & 2 & $0.5(0-1.4)$ & 0 & 0.40 \\
\hline lleus & 4 & 4 & $0.2(0-0.4)$ & 0 & 0.43 \\
\hline Abdominal compartment syndrome & 1 & 1 & $6.0(0.2-30)$ & NA & NA \\
\hline Necrotizing fasciitis & 1 & 1 & $3.0(0.1-16.0)$ & NA & NA \\
\hline
\end{tabular}

ARDS acute respiratory distress syndrome

*Intra-thoracic complications included pneumothorax, hemothorax, empyema, and pleural effusion(s)

${ }^{\dagger}$ Intra-abdominal collection included abscess, hematoma, urinoma, or biloma

the pooled risk of in-hospital death after SNOM for abdominal GSWs was $0.4 \%(95 \% \mathrm{CI}=0.2-0.6 \%)$. There was no evidence of heterogeneity in this estimate $\left(I^{2}=0 \%\right.$; homogeneity $p>0.99$ ) (Fig. 3).

Hospital length of stay Twenty-nine studies (70.7\%) reported the mean hospital LOS among patients who underwent SNOM, which varied from 2 to 20 days. The weighted average hospital LOS was 5.9 days. However, in patients with isolated abdominal GSWs without any associated extra-abdominal injuries, the weighted median hospital LOS was 2.3 days. Conversely, the weighted median hospital LOS in patients who failed SNOM or developed complications was 10.1 days.

\section{Subgroup and sensitivity analyses and meta-regression}

Table 4 details results of stratified meta-analyses and meta-regression of variables associated with failure of SNOM for abdominal GSWs. There was no difference in the pooled risk of SNOM failure between prospective and retrospective studies or those conducted in the USA, South Africa, or other countries. Risks of failure of SNOM were lowest in studies that evaluated patients with right thoracoabdomen $\left(3.4 \% ; 95 \% \mathrm{CI}=0-7.0 \% ; I^{2}=\right.$ $0 \%$; homogeneity $p=0.45)$, flank $(7.0 \%$; $95 \% \mathrm{CI}=3.9-$ $10.1 \%)$, and back (3.1\%; $95 \% \mathrm{CI}=0-6.5 \%)$ GSWs and highest in those that evaluated patients with anterior abdomen (13.2\%; 95\% CI =6.3-20.1\%) GSWs. Estimates of the pooled risk of failure in studies where serial physical examinations were reportedly done by attending trauma surgeons were approximately one-third that of those reported in studies where physical examinations were done by surgical residents. When studies were divided according to the policy of CT use, the pooled estimate of SNOM failure in studies of patients undergoing selective abdominopelvic CT was approximately double that of the pooled estimate of SNOM failure in studies of patients undergoing mandatory CT.

A sensitivity analysis excluding the results of studies that reported potentially overlapping patient outcome data (including those that may have overlapped with those recruited into the study that analyzed patients included in the NTDB) yielded a similar pooled estimate of the risk of failure of SNOM for abdominal GSWs $\left(6.7 \%, 95 \% \mathrm{CI}=2.5-10.9 \%, I^{2}=\right.$ $94.4 \%$, homogeneity $p<0.001)$ to the pooled estimate that included data from all studies reporting data on this outcome.

\section{Publication bias}

Inspection of the funnel plots of the reported risks of failure of SNOM versus the standard error across the included studies revealed that smaller studies may have reported higher risks of failure than larger studies (Fig. 4). Further, Begg's test was significant $(p=0.008)$ for funnel plot asymmetry. However, using Trim and Fill methods, the publication bias-adjusted summary estimate of the risk of failure of SNOM was unchanged $(7.2 \%$; $95 \% \mathrm{CI}=$ $4.2 \%-10.1 \%)$ from the unadjusted estimate $(7.0 \%$; $95 \%$ $\mathrm{CI}=3.9-10.1 \%)$, providing evidence that publication bias likely had little influence on the pooled results.

\section{Discussion}

This systematic review of 41 studies involving 22,847 civilians with abdominal GSWs is the first to comprehensively meta-analyze outcomes associated with use of SNOM in this patient population. Our findings suggest that highly experienced trauma centers have safely treated greater than 


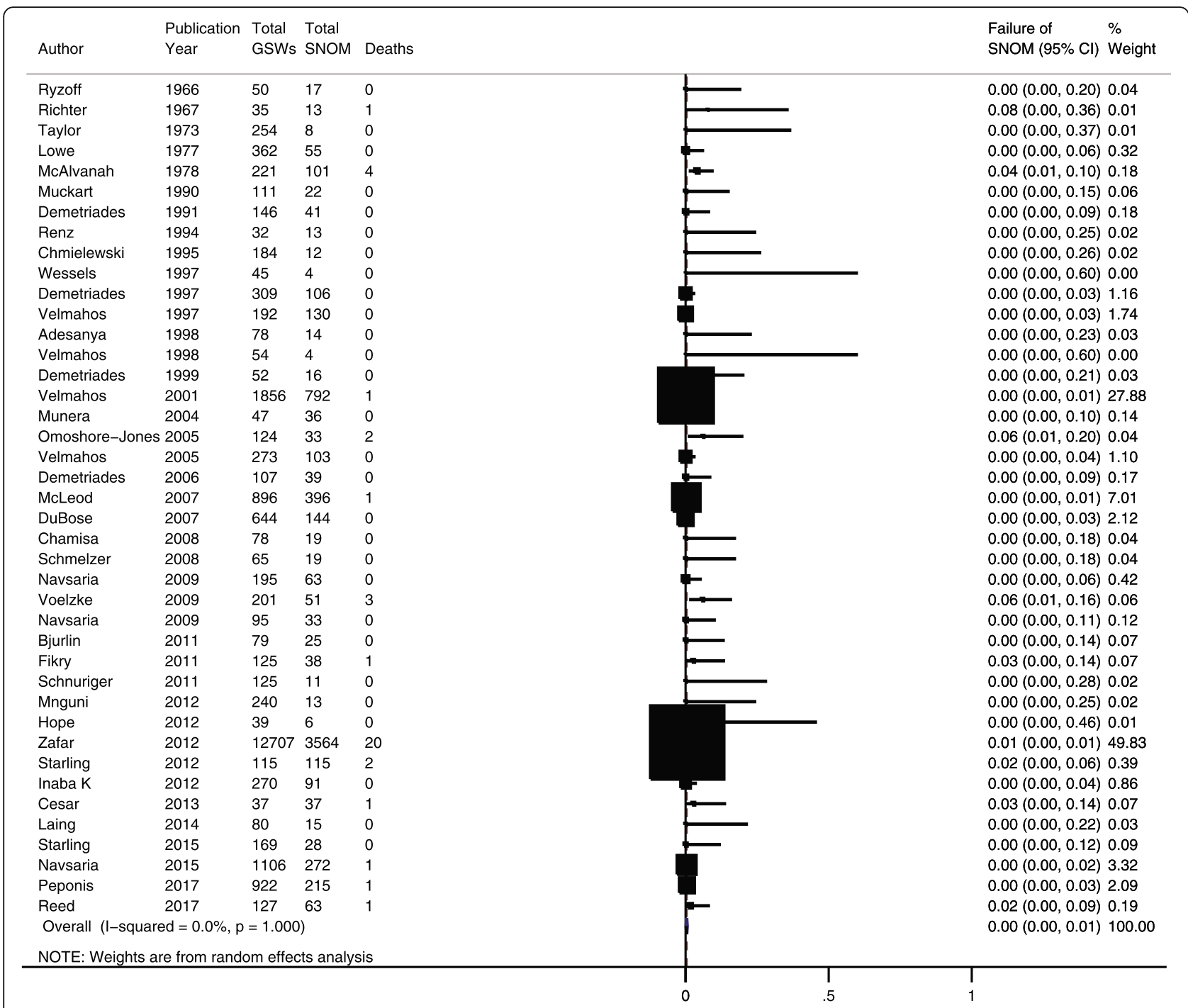

Fig. 3 Pooled risk of mortality in civilians undergoing selective nonoperative management of abdominal gunshot wounds

90\% of the patients included in these studies nonoperatively. Importantly, in all studies, only hemodynamically stable patients without a reduced level of consciousness and no signs of peritonitis were selected for SNOM. SNOM may be more successful among patients with GSWs to the right thoracoabdomen, flank, or back than the anterior abdomen and when serial physical examinations are performed by attending trauma surgeons. This practice also appears to be more successful in patients who undergo mandatory abdominopelvic CT scans and in those with injuries proven to involve the kidney on imaging. Although SNOM has been linked with development of atelectasis, GSW infections, and biliary fistulae in patients with GSWs to the liver, these complications are uncommon and appear to be less frequent than that historically reported after mandatory laparotomy in similar patient populations [69-71].
As most of the included studies were conducted at high-volume, level 1 , academic trauma centers in the USA, our results may not be generalizable to centers without the necessary structures and processes to manage these patients. Many of the centers conducting research on SNOM described dedicated, monitored areas to observe and examine patients with abdominal GSWs in the initial hours after injury (and therefore these systems may be required to assure timely rescue of patients who fail SNOM). Of those who failed SNOM, the most frequent reasons for delayed laparotomy included development of peritonitis or worsening abdominal tenderness, each of which was mostly commonly detected within the first $24-48 \mathrm{~h}$ of admission through close clinical monitoring. It is interesting that $28 \%$ of patients who failed SNOM across the included studies underwent unnecessary laparotomy, which suggests that success of 
Table 4 Stratified meta-analyses and meta-regression of variables associated with failure of selective nonoperative management of abdominal gunshot wounds

\begin{tabular}{|c|c|c|c|c|c|}
\hline Comparison & & $\begin{array}{l}\text { No. of } \\
\text { studies }\end{array}$ & $\begin{array}{l}\text { Pooled estimate of SNOM failure, \% } \\
(95 \% \mathrm{Cl})\end{array}$ & $\begin{array}{l}P^{2} \text { statistic, } \\
\%\end{array}$ & $\begin{array}{l}\text { Meta-regression } p \\
\text { value }\end{array}$ \\
\hline \multirow{5}{*}{$\begin{array}{l}\text { Study temporality and } \\
\text { setting }\end{array}$} & Prospective & 22 & $4.3(2.7-6.0)$ & 24.4 & 0.27 \\
\hline & Retrospective & 19 & $8.0(2.8-13.3)$ & 95.6 & \\
\hline & Conducted in the USA & 29 & $8.1(4.2-12.1)$ & 94.3 & NA \\
\hline & Conducted in South Africa & 8 & $4.7(2.5-6.9)$ & 0 & $0.32^{*}$ \\
\hline & $\begin{array}{l}\text { Conducted in other } \\
\text { countries }\end{array}$ & 4 & $7.0(3.9-10.1)$ & 0 & $0.35^{*}$ \\
\hline \multirow{7}{*}{$\begin{array}{l}\text { Study patient injury } \\
\text { patterns }\end{array}$} & Abdominal GSWs & 24 & $7.3(3.0-11.5)$ & 95.1 & NA \\
\hline & Liver GSWs & 5 & $6.6(0.0-13.3)$ & 49.8 & $0.99^{\dagger}$ \\
\hline & Renal GSWs & 6 & $3.5(0-7.3)$ & 0 & $0.39^{\dagger}$ \\
\hline & Back GSWs & 1 & $3.1(0-6.5)$ & NA & $0.52^{\dagger}$ \\
\hline & Flank GSWs & 1 & $7.0(3.9-10.1)$ & NA & $0.09^{+}$ \\
\hline & Anterior abdomen GSWs & 1 & $13.2(6.3-20.1)$ & NA & $0.51^{\dagger}$ \\
\hline & $\begin{array}{l}\text { Right thoracoabdomen } \\
\text { GSWs }\end{array}$ & 3 & $3.4(0-7.0)$ & 0 & $0.45^{\dagger}$ \\
\hline \multirow[t]{4}{*}{ Reported SNOM practices } & $\begin{array}{l}\text { SNOM by attending } \\
\text { surgeon }\end{array}$ & 5 & $2.1(7.8-16.3)$ & 0 & 0.07 \\
\hline & SNOM by surgical resident & 4 & $7.2(3.9-10.5)$ & 89.5 & \\
\hline & Mandatory use of CT & 15 & $4.2(1.9-6.5)$ & 33.5 & 0.08 \\
\hline & Selective use of CT & 19 & $8.3(3.9-12.8)$ & 94.4 & \\
\hline
\end{tabular}

Cl confidence interval, CT computed tomography, GSW gunshot wound, SNOM selective nonoperative management

*Compared to the estimate associated with USA

${ }^{+}$Compared to abdominal GSWs

SNOM may potentially benefit from studies focused on creating appropriate indications for delayed operation during SNOM [72].

Our findings identified that mandatory use of abdominopelvic CT was associated with a failure rate of SNOM that was approximately half of that reported for selective use of CT scanning. Further, the number of unnecessary laparotomies in patients who failed SNOM was higher in studies that used a selective policy of CT scanning. These findings suggest that use of CT may confer a higher degree of confidence to surgeons managing patients with an equivocal clinical exam or concerning bullet trajectory.

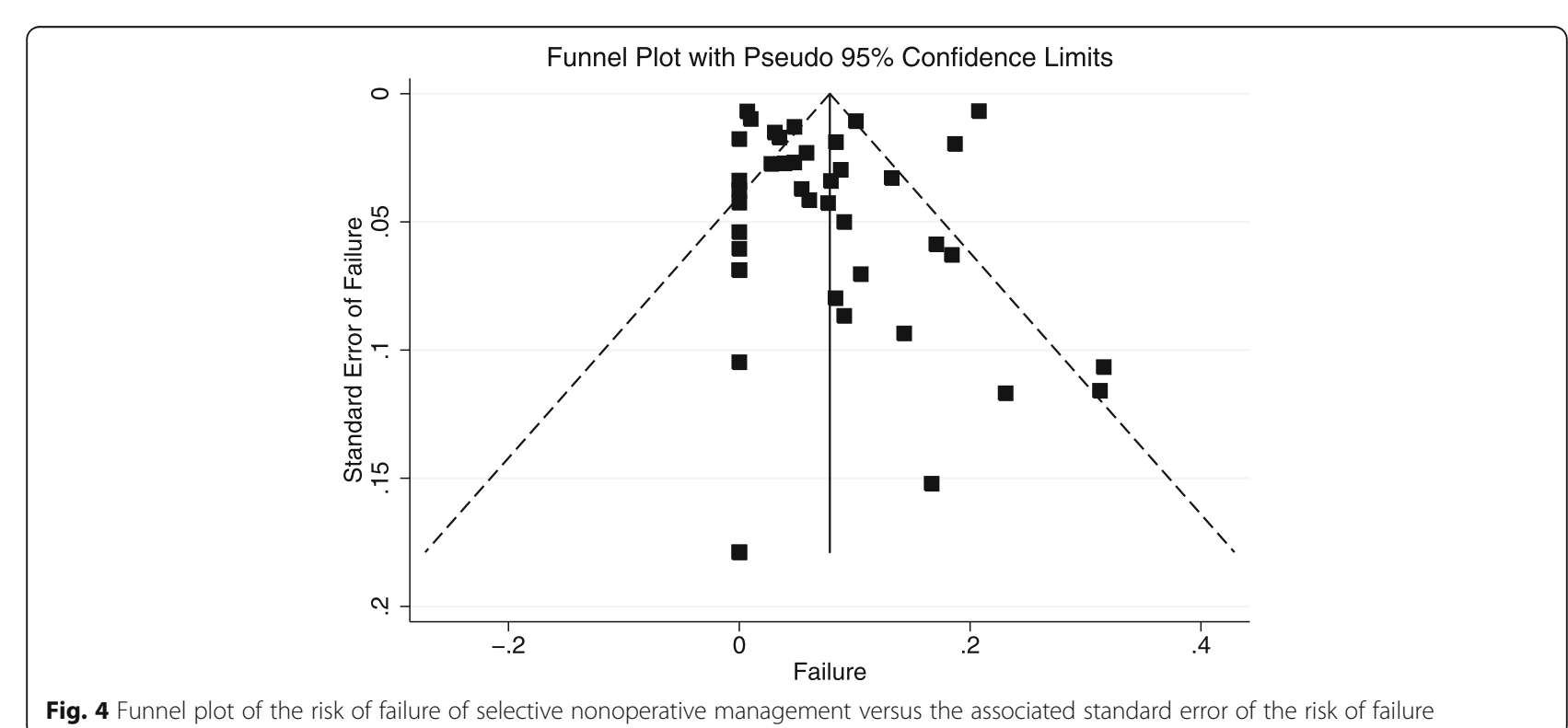

Fig. 4 Funnel plot of the risk of failure of selective nonoperative management versus the associated standard error of the risk of failure 
Whereas CT may be argued to be of minimal help to patients with anterior abdominal GSWs who are clearly hemodynamically stable and have no abdominal tenderness, there are situations in which CT will provide much-needed, additional information to guide surgical decision-making. These include patients with suspected tangential abdominal wounds, back or flank GSWs who may have retroperitoneal injuries, or RUQ GSWs who may have isolated hepatic trauma. These findings may support the level 2 recommendation made by the Eastern Association for the Surgery of Trauma in their 2010 guideline that abdominopelvic $\mathrm{CT}$ be strongly considered in patients undergoing SNOM of penetrating abdominal wounds (especially those with GSWs to the flank, back, and RUQ) [13].

Common complications of SNOM, as reported across the included studies, were frequently relatively minor and may be divided into those that are thoracic (pneumothorax, hemothorax, or pleural effusion) and abdominal (GSW infection and biliary fistulae in patients with GSWs to the liver). As the risk of complications in patients undergoing mandatory laparotomy has been reported to be as high as $22-41 \%[4,5]$, the frequency of complications in patients undergoing SNOM in experienced trauma centers (13\% across 11 studies) may be similar or even lower than mandatory laparotomy. However, when patients develop complications after SNOM for abdominal GSWs, their mean hospital LOS appears to increase from approximately 2 (in patients without associated extra-abdominal injuries) or 6 (in patients with associated extra-abdominal injuries) to 10 days. In particular, SNOM of liver GSWs was associated with a risk of biliary fistulae (6.3\%) and pulmonary complications (15.9\%).

This systematic review has several limitations. First, we identified no controlled studies comparing outcomes of conducting SNOM versus mandatory laparotomy in hemodynamically stable patients with abdominal GSWs without diffuse peritonitis. Second, although we were unable to determine the amount of duplication of included patient outcome data with certainty, a sensitivity analysis excluding the results of studies that reported potentially overlapping data yielded a similar pooled estimate of the failure of SNOM. Third, few studies examined associations between the use of angioembolization/endovascular interventions and SNOM failure or provided details of whether reported complications were directly attributable to a failure of SNOM. Fourth, some studies did not report their methods of conducting SNOM. Thus, the management of each case was ultimately dictated by attending surgeons, which likely introduced unmeasured variability in practice and outcomes. Finally, some studies included patients in the SNOM group that only had tangential and superficial abdominal GSWs without peritoneal breach, which likely improved the reported outcomes of SNOM.

\section{Conclusion}

In conclusion, this systematic review and meta-analysis of 41 cohort studies involving 22,847 patients with abdominal GSWs (of whom 6777 patients underwent SNOM) suggests that SNOM is safe when conducted in experienced trauma centers. The practice may be especially useful when serial physical examinations are performed by attending trauma surgeons and in patients with GSWs involving the right thoracoabdomen, flank, or back instead of the anterior abdomen and those proven to involve the kidney on imaging. The most frequent reasons for delayed laparotomy in patients undergoing SNOM include development of peritonitis or worsening abdominal tenderness, each of which is likely to be detected within the first 24$48 \mathrm{~h}$ of admission across hospitals with the necessary experience and/or resources to ensure timely rescue of patients who fail SNOM. Mandatory use of abdominopelvic CT may increase the success of SNOM, potentially by increasing clinician confidence when managing patients with an equivocal clinical examination or identifying/characterizing retroperitoneal/isolated hepatic injuries in those with GSWs to the flank, back, or RUQ.

\section{Additional files}

Additional file 1: Digital content S1. Completed Meta-Analysis of Observational Studies in Epidemiology (MOOSE) checklist. (DOCX $16 \mathrm{~kb}$ )

Additional file 2: Digital content S2. Literature search strategies. (DOCX $15 \mathrm{~kb}$ )

Additional file 3: Digital content S3. Indications for delayed laparotomy in patients undergoing selective nonoperative management and findings at the time of operation. (DOCX $29 \mathrm{~kb}$ )

\section{Abbreviations}

Cl: Confidence interval; CT: Computed tomography; GSW: Gunshot wound; ISS: Injury Severity Scale; LOS: Length of stay; MeSH: Medical Subject Heading; MOOSE: Meta-analysis of Observational Studies in Epidemiology; QUIPS: Quality in Prognosis Studies; RUQ: Right upper quadrant; SNOM: Selective nonoperative management; WBC: White blood cell

\section{Acknowledgements}

None.

\section{Funding}

This study was supported by an Alberta Innovates - Health Solutions Clinician Fellowship Award, a Knowledge Translation (KT) Canada Strategic Training in Health Research Fellowship, a KT Canada Research Stipend, and funding from the Canadian Institutes of Health Research (each of which were awarded to DJR). These funders had no role in the design or conduct of the study; collection, management, analysis, or interpretation of the data; or preparation, review, or approval of the manuscript.

Availability of data and materials

ANAR and FAAH had full access to all data in the study and take responsibility for the integrity of the data and the accuracy of the data analyses. 


\section{Authors' contributions}

ANAR, FAAH, and DJR conceived and designed the study and created the study protocol, which was critically revised by all authors. ANAR, FAAH, and JMB performed literature search, full-text screening, and data extraction. ANAR and FAAH performed the risk of bias assessment and statistical analysis. ANAR and DJR wrote the manuscript, which was critically revised by DJR and then iteratively by all other authors. The study was supervised by DJR. All authors reviewed and approved the final manuscript.

\section{Ethics approval and consent to participate}

Not applicable.

\section{Consent for publication}

Not applicable.

\section{Competing interests}

AWK has received funding from Kinetic Concepts Incorporated for a randomized controlled trial comparing the ABThera ${ }^{\mathrm{TM}}$ Open Abdomen Negative Pressure Therapy system and Barker's vacuum pack temporary abdominal closure techniques. He has also received travel funding from LifeCell Corp., Syntheses, and Innovative Trauma Care. The other authors have no conflicts of interest to declare.

\section{Publisher's Note}

Springer Nature remains neutral with regard to jurisdictional claims in published maps and institutional affiliations.

\section{Author details}

${ }^{1}$ Department of Surgery, University of Calgary, Calgary, Alberta, Canada. ${ }^{2}$ Department of Critical Care Medicine, University of Calgary, Calgary, Alberta, Canada. ${ }^{3}$ Regional Trauma Program, University of Calgary and the Foothills Medical Centre, Calgary, Alberta, Canada. ${ }^{4}$ Division of Trauma, Emergency Surgery, and Critical Care, Department of Surgery, Massachusetts General Hospital, Boston, MA, USA. ${ }^{5}$ Department of Surgery, University of Cape Town Health Sciences Faculty, Cape Town, South Africa. ${ }^{6}$ Trauma Centre, Groote Schuur Hospital, Observatory, Cape Town, South Africa. ${ }^{7}$ Division of Vascular and Endovascular Surgery, Department of Surgery, University of Ottawa, The Ottawa Hospital, Civic Campus, Room A280, 1053 Carling Avenue, Ottawa, Ontario K1Y 4E9, Canada.

\section{Received: 21 August 2018 Accepted: 5 November 2018}

\section{Published online: 27 November 2018}

\section{References}

1. Shaftan GW. Selective conservatism in penetrating abdominal trauma. J Trauma. 1969;9:1026-8.

2. Singh N, Hardcastle TC. Selective non operative management of gunshot wounds to the abdomen: a collective review. Int Emerg Nurs. 2015;23(1):22-31.

3. Nance FC, Cohn I Jr. Surgical judgment in the management of stab wounds of the abdomen: a retrospective and prospective analysis based on a study of 600 stabbed patients. Ann Surg. 1969;170:569-80.

4. Sosa JL, Arrilaga A, Puente I, et al. Laparoscopy in 121 consecutive patients with abdominal gunshot wounds. J Trauma. 1995;39:501-4.

5. Ross SE, Dragon GM, O'Malley KF, et al. Morbidity of negative coeliotomy in trauma. Injury. 1995;26:393-4

6. Renz BM, Feliciano DV. The length of hospital stay after an unnecessary laparotomy for trauma: a prospective study. J Trauma. 1996;40(2):187-90.

7. Danto LA, Thomas CW, Gorenbein S, et al. Penetrating torso injuries: the role of paracentesis and lavage. Am Surg. 1977;43(3):164-70.

8. Nance FC, Wennar MH, Johnson LW, et al. Surgical judgment in the management of penetrating wounds of the abdomen: experience with 2212 patients. Ann Surg. 1974;197(5):639-46.

9. Navsaria PH, Berli JU, Edu S, et al. Non-operative management of abdominal stab wounds--an analysis of 186 patients. S Afr J Surg. 2007; 45(4):128-30 132

10. Saadia R, Degiannis E. Non-operative treatment of abdominal gunshot injuries. Br J Surg. 2000;87:393-7.

11. Múnera F, Morales C, Soto JA, et al. Gunshot wounds of abdomen: evaluation of stable patients with triple-contrast helical CT. Radiology. 2004; 231(2):399-405.
12. Velmahos GC, Constantinou C, Tillou A, et al. Abdominal computed tomographic scan for patients with gunshot wounds to the abdomen selected for nonoperative management. J Trauma. 2005;59(5):1155-60.

13. Como JJ, Bokhari F, Chiu WC, et al. Practice management guidelines for selective nonoperative management of penetrating abdominal trauma. J Trauma. 2010;68(3):721-33.

14. Moher D, Liberati A, Tetzlaff J, et al. Preferred reporting items for systematic reviews and meta-analyses: the PRISMA statement. Int J Surg. 2010;8(5):336-41.

15. Stroup DF, Berlin JA, Morton SC, et al. Meta-analysis of observational studies in epidemiology: a proposal for reporting. Meta-analysis Of Observational Studies in Epidemiology (MOOSE) group. JAMA. 2000;283(15):2008-12.

16. Dekkers OM, Egger M, Altman DG, et al. Distinguishing case series from cohort studies. Ann Intern Med. 2012;156:37-40.

17. Landis JR, Koch GG. The measurement of observer agreement for categorical data. Biometrics. 1977;33(1):159-74

18. Marx JA, Isenhour JL. Abdominal trauma. In: Marx JA, editor. Rosen's emergency medicine: concepts and clinical practice. 6 th ed. Philadelphia: Mosby; 2006.

19. Hayden JA, Côté $P$, Bombardier C. Evaluation of the quality of prognosis studies in systematic reviews. Ann Intern Med. 2006;144(6):427-37.

20. Clopper C, Pearson ES. The use of confidence or fiducial limits illustrated in the case of the binomial. Biometrika. 1934;26(2):404-13.

21. Sweeting MJ, Sutton AJ, Lambert PC. What to add to nothing? Use and avoidance of continuity corrections in meta-analysis of sparse data. Stat Med. 2004:23:1351-75.

22. DerSimonian R, Laird N. Meta-analysis in clinical trials. Control Clin Trials. 1986;7:177-88.

23. Deeks JJ, Altman DG, Bradburn MJ. Statistical methods for examining heterogeneity and combining results from several studies in meta-analysis. In: Egger M, Smith GD, Altman GD, editors. Systematic reviews in health care: meta-analysis in context. London: BMJ Publishing Group; 2001. p. 285-312.

24. Higgins JPT, Thompson SG, Deeks JJ, et al. Measuring inconsistency in meta-analyses. BMJ. 2003;17:557-60.

25. Begg CB, Mazumdar M. Operating characteristics of a rank correlation test for publication bias. Biometrics. 1994:50:1088-101.

26. Duval SJ, Tweedie RL. A non-parametric "trim and fill" method of accounting for publication bias in meta-analysis. J Am Stat Assoc. 2000; 95:89-98.

27. Duval SJ, Tweedie RL. Trim and fill: a simple funnel plot based method of testing and adjusting for publication bias in meta-analysis. Biometrics. 2000; 56:455-63.

28. Sterne JA, Egger M, Smith GD. Investigating and dealing with publication and other biases. In: Egger M, Smith GD, Altman GD, editors. Systematic reviews in health care: meta-analysis in context: BMJ Publishing Group; 2001. p. 189-208.

29. Cosic N, Roberts DJ, Stelfox HT. Efficacy and safety of damage control in experimental animal models of injury: protocol for a systematic review and meta-analysis. Syst Rev. 2014:3:136.

30. Laing GL, Skinner DL, Bruce JL, et al. A multi faceted quality improvement programme results in improved outcomes for the selective non-operative management of penetrating abdominal trauma in a developing world trauma centre. Injury. 2014:45(1):327-32.

31. Fikry K, Velmahos GC, Bramos A, et al. Successful selective nonoperative management of abdominal gunshot wounds despite low penetrating trauma volumes. Arch Surg. 2011;146(5):528-32.

32. Bjurlin MA, Jeng El, Goble SM, et al. Comparison of nonoperative management with renorrhaphy and nephrectomy in penetrating renal injuries. J Trauma. 2011;71(3):554-8.

33. Navsaria PH, Nicol AJ. Selective nonoperative management of kidney gunshot injuries. World J Surg. 2009;33(3):553-7.

34. Wessells H, McAninch JW, Meyer A, et al. Criteria for nonoperative treatment of significant penetrating renal lacerations. J Urol. 1997;157(1):24-7.

35. Peponis $T$, Kasotakis $G, Y u$ J, et al. Selective nonoperative management of abdominal gunshot wounds from heresy to adoption: a multicenter study of the Research Consortium of New England Centers for Trauma (ReCoNECT). J Am Coll Surg. 2017;224(6):1036-45.

36. Mnguni MN, Muckart DJ, Madiba TE. Abdominal trauma in Durban, South Africa: factors influencing outcome. Int Surg. 2012;97(2):161-8.

37. Voelzke BB, McAninch JW. Renal gunshot wounds: clinical management and outcome. J Trauma. 2009;66(3):593-600. 
38. Demetriades D, Hadjizacharia P, Constantinou C, et al. Selective nonoperative management of penetrating abdominal solid organ injuries. Ann Surg. 2006;244(4):620-8.

39. Velmahos GC, Demetriades $D$, et al. Selective nonoperative management in 1,856 patients with abdominal gunshot wounds: should routine laparotomy still be the standard of care? Ann Surg. 2001;234(3):395-403.

40. Starling SV, Rodrigues Bde L, Martins MP, et al. Non operative management of gunshot wounds on the right thoracoabdomen. Rev Col Bras Cir. 2012; 39(4):286-94.

41. Chmielewski GW, Nicholas JM, Dulchavsky SA, et al. Nonoperative management of gunshot wounds of the abdomen. Am Surg. 1995; 61(8):665-8

42. Renz BM, Feliciano DV. Gunshot wounds to the right thoracoabdomen: a prospective study of nonoperative management. J Trauma. 1994;37(5):737-44.

43. Velmahos GC, Demetriades D, Foianini $E$, et al. A selective approach to the management of gunshot wounds to the back. Am J Surg. 1997;174(3):342-6.

44. MacLeod J, Freiberger D, Lewis F, et al. What is the optimal observation time for a penetrating wound to the flank? Am Surg. 2007;73(1):25-31.

45. Navsaria PH, Nicol AJ, Edu S, et al. Selective nonoperative management in 1106 patients with abdominal gunshot wounds: conclusions on safety, efficacy, and the role of selective $C T$ imaging in a prospective single-center study. Ann Surg. 2015;261(4):760-4.

46. Inaba K, Branco BC, Moe D, et al. Prospective evaluation of selective nonoperative management of torso gunshot wounds: when is it safe to discharge? J Trauma Acute Care Surg. 2012;72(4):884-91.

47. Navsaria PH, Nicol AJ, Krige JE, et al. Selective nonoperative management of liver gunshot injuries. Ann Surg. 2009;249(4):653-6.

48. Chamisa I. Civilian abdominal gunshot wounds in Durban, South Africa: a prospective study of 78 cases. Ann R Coll Surg Engl. 2008;90(7):581-6.

49. Omoshoro-Jones JA, Nicol AJ, Navsaria PH. Selective non-operative management of liver gunshot injuries. Br J Surg. 2005:92(7):890-5.

50. Demetriades D, Gomez H, Chahwan S. Gunshot injuries to the liver: the role of selective nonoperative management. J Am Coll Surg. 1999;188(4):343-8.

51. Demetriades D, Velmahos G, Cornwell E, et al. Selective nonoperative management of gunshot wounds of the anterior abdomen. Arch Surg. 1997;132(2):178-83.

52. Demetriades D, Charalambides D, Lakhoo M, et al. Gunshot wound of the abdomen: role of selective conservative management. $\mathrm{Br} J$ Surg. 1991;78(2):220-2.

53. Muckart DJ, Abdool-Carrim AT, King B. Selective conservative management of abdominal gunshot wounds: a prospective study. $\mathrm{Br}$ J Surg. 1990;77(6):652-5.

54. McAlvanah MJ, Shaftan GW. Selective conservatism in penetrating abdominal wounds: a continuing reappraisal. J Trauma. 1978;18(3):206-12.

55. Lowe RJ, Saletta JD, Read DR, et al. Should laparotomy be mandatory or selective in gunshot wounds of the abdomen? J Trauma. 1977;17(12):903-7.

56. Ryzoff Rl, Shaftan GW, Herbsman H. Selective conservatism in penetrating abdominal trauma. Surgery. 1966;59(4):650-3.

57. Adesanya AA, Afolabi IR, da Rocha-Afodu JT. Civilian abdominal gunshot wounds in Lagos. J R Coll Surg Edinb. 1998;43(4):230-4.

58. Richter RM, Zaki MH. Selective conservative management of penetrating abdominal wounds. Ann Surg. 1967;166(2):238-44.

59. Starling SV, de Azevedo Cl, Santana AV, et al. Isolated liver gunshot injuries: nonoperative management is feasible? Rev Col Bras Cir. 2015:42(4):238-43.

60. DuBose J, Inaba K, Teixeira PG, et al. Selective non-operative management of solid organ injury following abdominal gunshot wounds. Injury. 2007; 38(9):1084-90

61. Cesar BP, Starling SV, Drumond DA. Non-operative management of renal gunshot wounds. Rev Col Bras Cir. 2013;40(4):330-4.

62. Zafar SN, Rushing A, Haut ER, et al. Outcome of selective non-operative management of penetrating abdominal injuries from the North American National Trauma Database. Br J Surg. 2012;99(Suppl 1):155-64.

63. Hope WW, Smith ST, Medieros B, et al. Non-operative management in penetrating abdominal trauma: is it feasible at a level II trauma center? J Emerg Med. 2012:43(1):190-5.

64. Schmelzer TM, Mostafa G, Gunter OL Jr, et al. Evaluation of selective treatment of penetrating abdominal trauma. J Surg Educ. 2008;65(5):340-5.

65. Reed BL, Patel NJ, McDonald AA, et al. Selective nonoperative management of abdominal gunshot wounds with isolated solid organ injury. Am J Surg. 2017;213(3):583-5.
66. Schnüriger $B$, Talving $P$, Barbarino $R$, et al. Current practice and the role of the $\mathrm{CT}$ in the management of penetrating liver injuries at a Level I trauma center. J Emerg Trauma Shock. 2011:4(1):53-7.

67. Velmahos GC, Demetriades D, Cornwell EE, et al. Selective management of renal gunshot wounds. Br J Surg. 1998;85(8):1121-4.

68. Taylor FW. Gunshot wounds of the abdomen. Ann Surg. 1973;177(2):174-7.

69. Renz BM, Feliciano DV. Unnecessary laparotomies for trauma: a prospective study of morbidity. J Trauma. 1995;38:350-6.

70. Moore EE, Moore JB, Van Duzer-Moore S, et al. Mandatory laparotomy for gunshot wounds penetrating the abdomen. Am J Surg. 1980;140(6):847-51.

71. Weigelt JA, Kingman RG. Complications of negative laparotomy for trauma. Am J Surg. 1988;156(6):544-7.

72. Wallis A, Kelly MD, Jones L. Angiography and embolisation for solid abdominal organ injury in adults - a current perspective. World J Emerg Surg. 2010;5:18
Ready to submit your research? Choose BMC and benefit from:

- fast, convenient online submission

- thorough peer review by experienced researchers in your field

- rapid publication on acceptance

- support for research data, including large and complex data types

- gold Open Access which fosters wider collaboration and increased citations

- maximum visibility for your research: over $100 \mathrm{M}$ website views per year

At BMC, research is always in progress.

Learn more biomedcentral.com/submissions 